\title{
NÁO CIRCULA
}

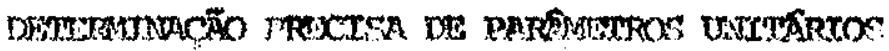

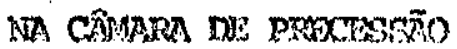

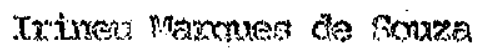

TPTST

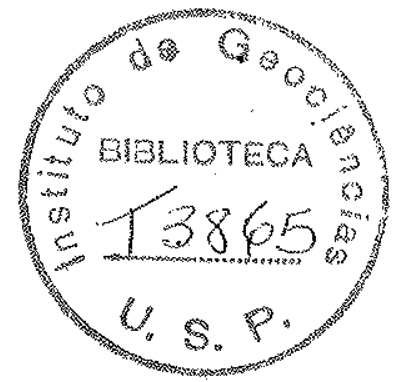

x. Mromono

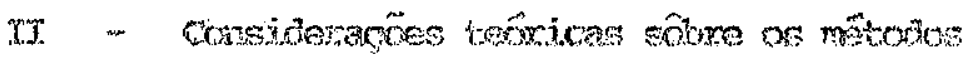

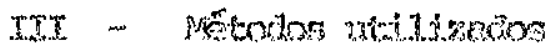

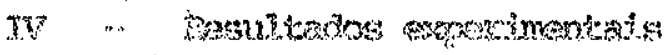

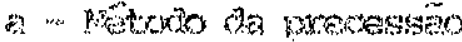

$$
\begin{aligned}
& \text { b. Mtrodo do no }
\end{aligned}
$$

$7-\infty$ congilowess

7x. -.. resemo

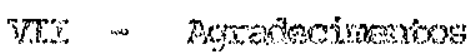

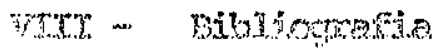

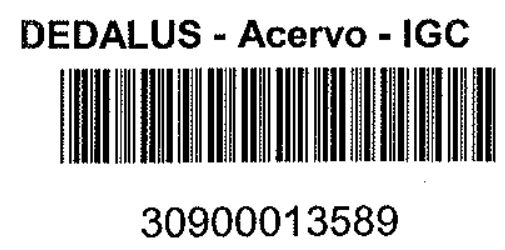

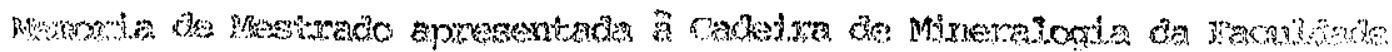

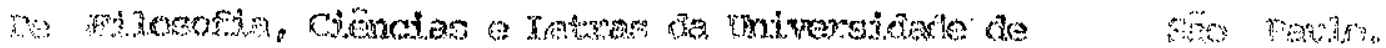




\section{Imstowotio}

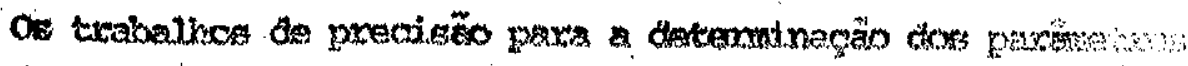

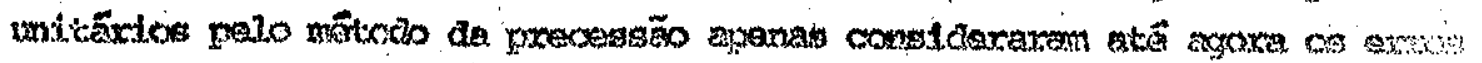

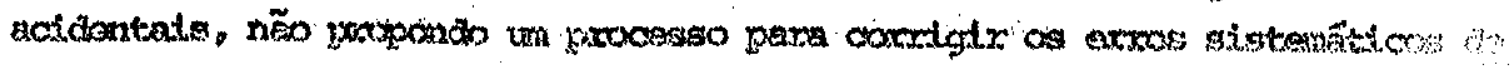

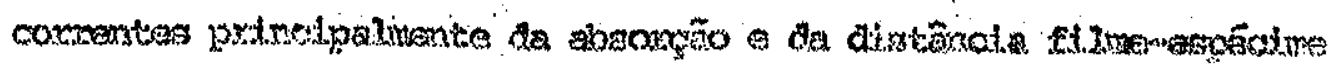

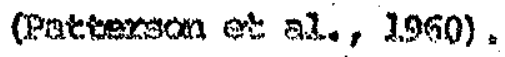

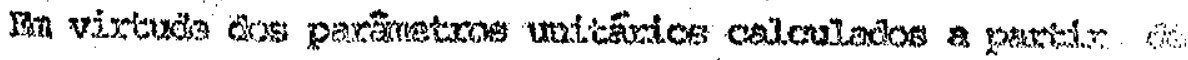

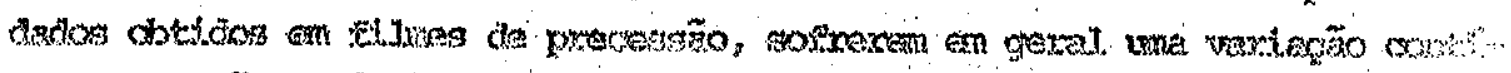

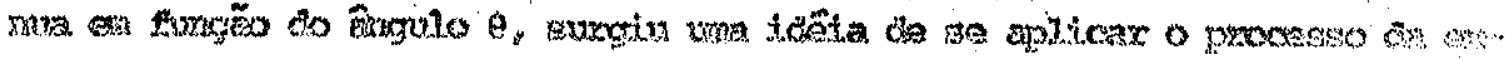

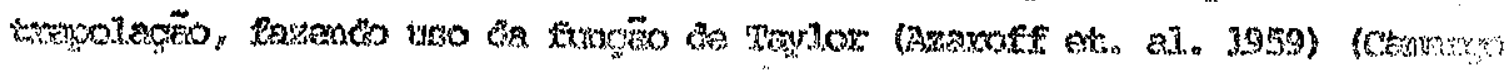

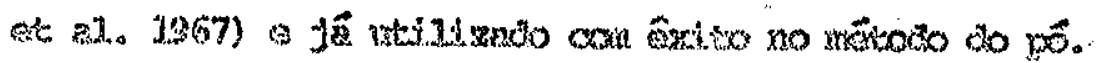

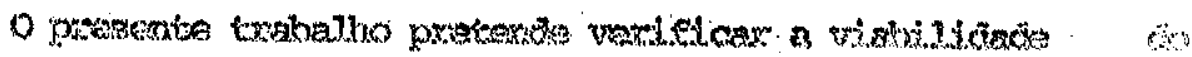

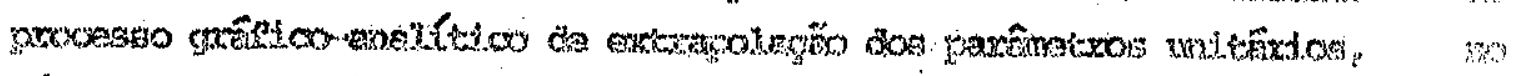

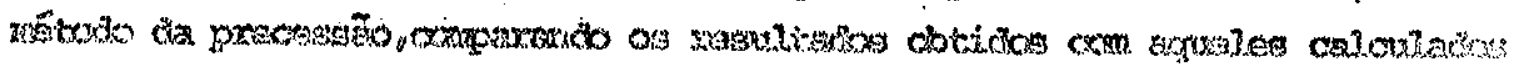

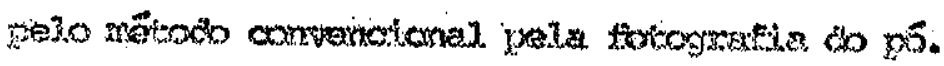

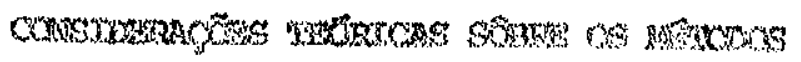

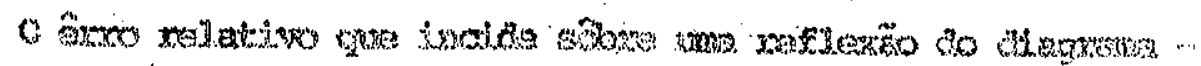

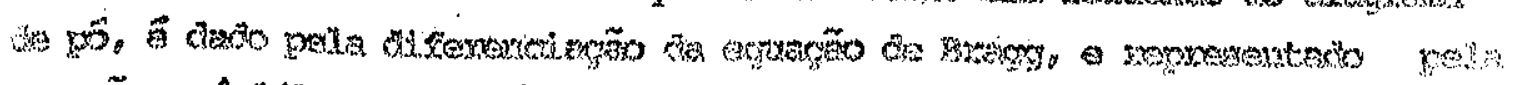

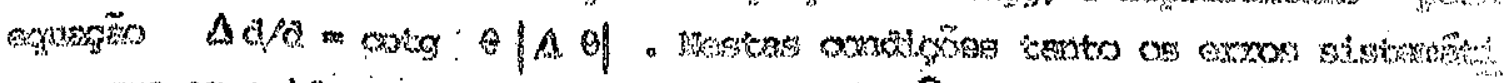

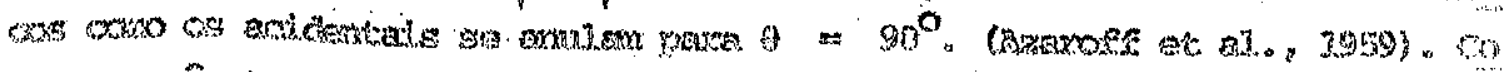

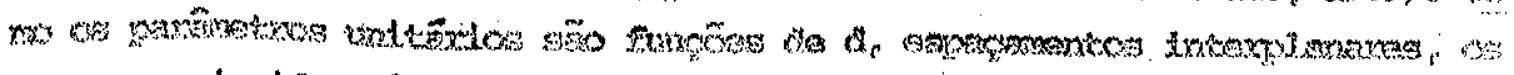

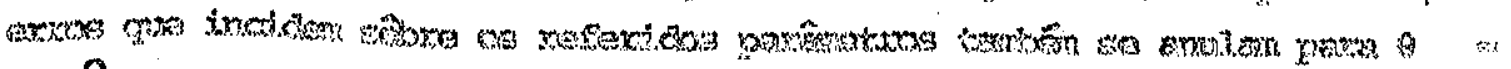
$=0^{\circ}$.

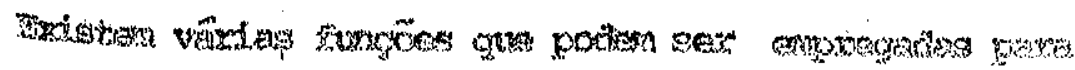

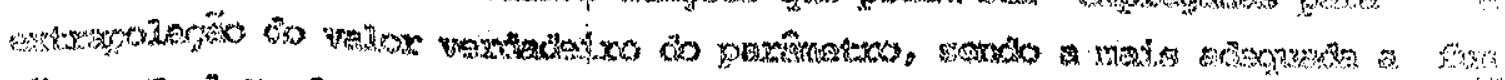
fy

$$
\operatorname{sen} \theta=2 / 2 \cos ^{2} \theta / \operatorname{son}^{2} 2+\cos ^{2}+10
$$




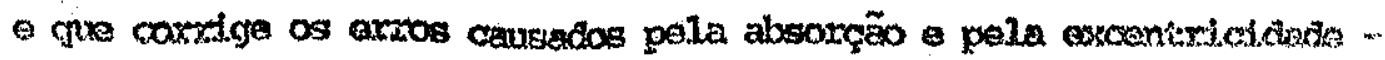

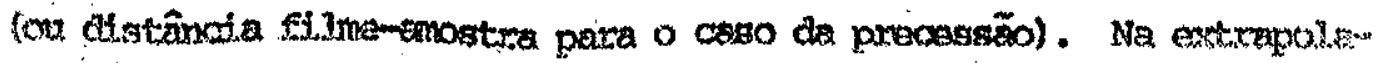

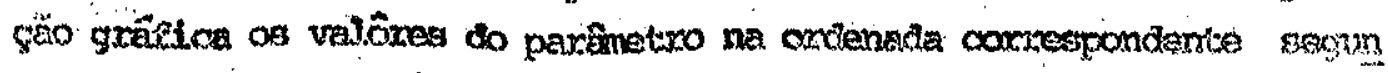

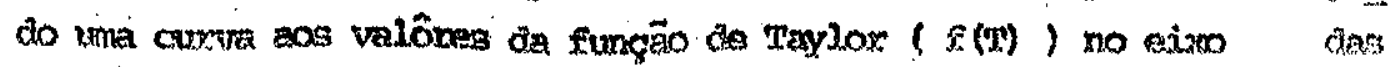
aboitssas.

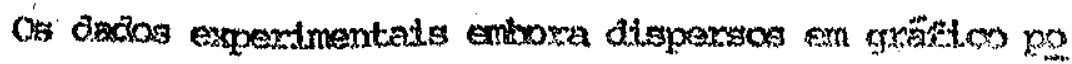

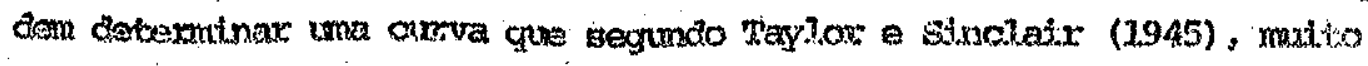
se aprontma do ma mba, o que peranite a axtrapolaçño e adotar s processo grátro-analitico (camango et al. 1967). cue formeco palas

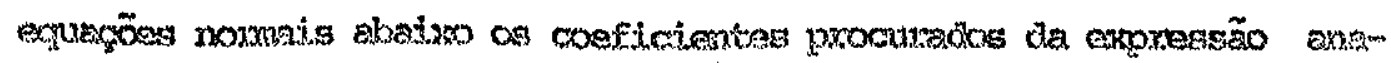
Intica da xera $y=t x+p=$

$$
\begin{aligned}
& t x_{i}^{2}+p \sum x_{j}=\sum x_{i} x_{j} \\
& t \sum x_{j}+p=\sum y_{i}
\end{aligned}
$$

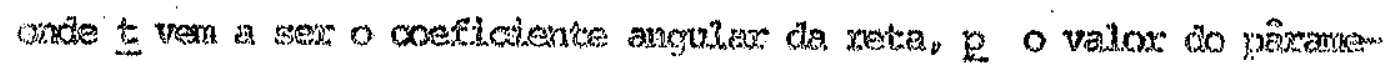

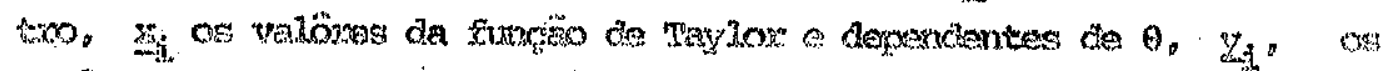

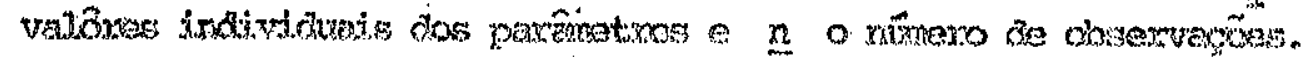

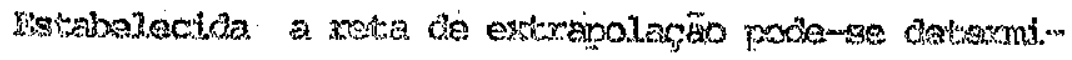

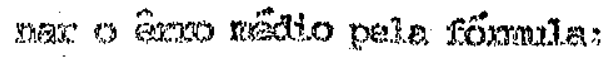

$$
=\frac{\sum_{n}^{2} x_{i}^{2}}{x_{(x-3)}(x)}
$$

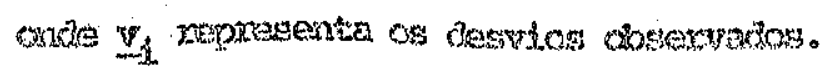

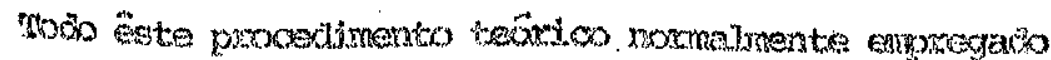

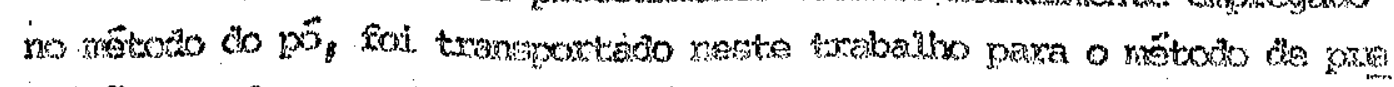

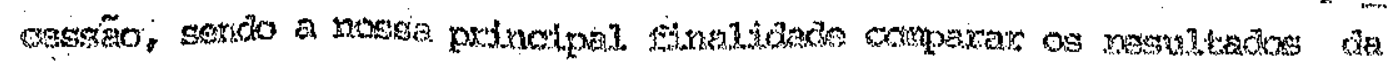

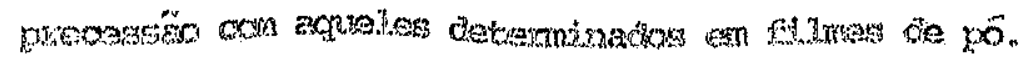

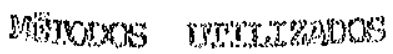

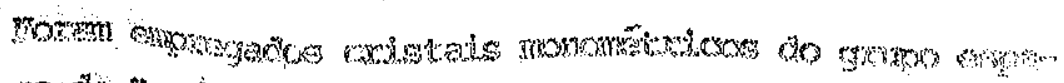

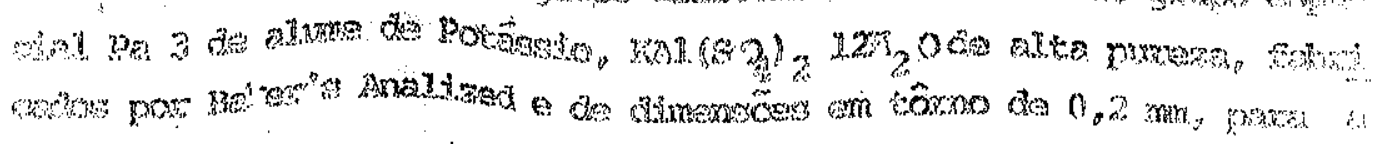




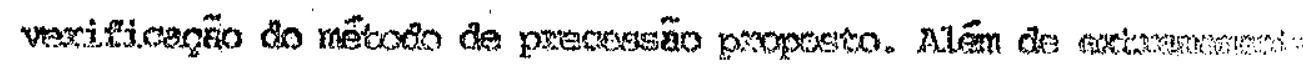

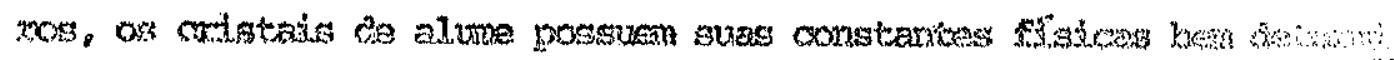

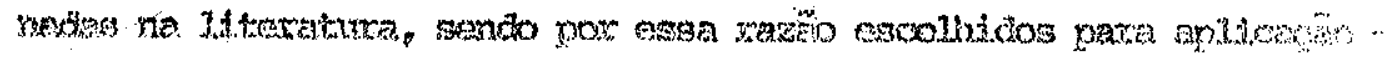
co grateresso.

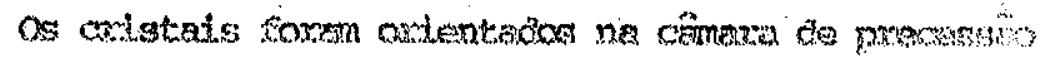

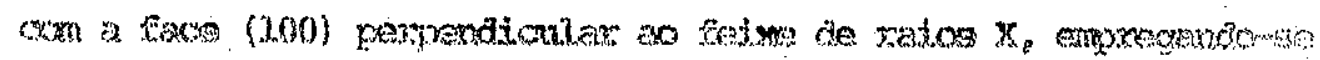

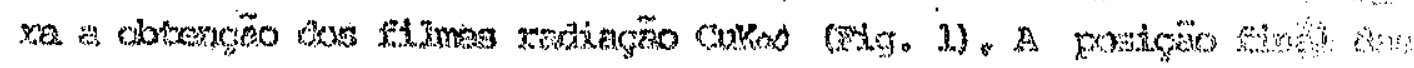

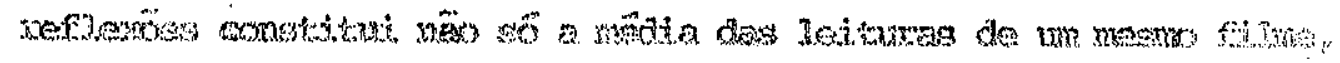

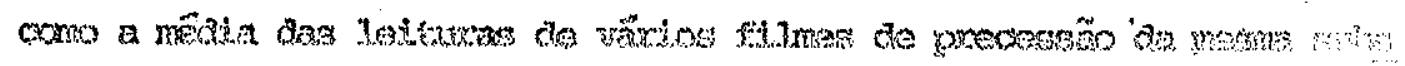
Foncila.

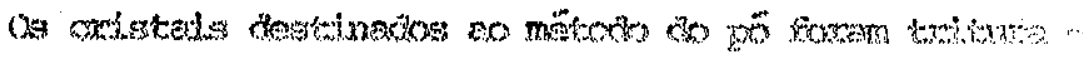

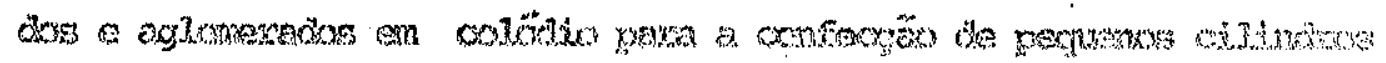

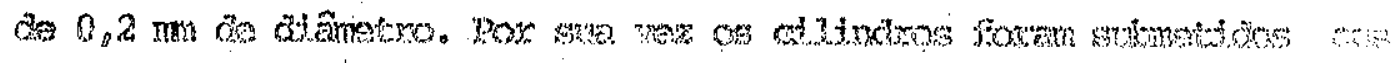

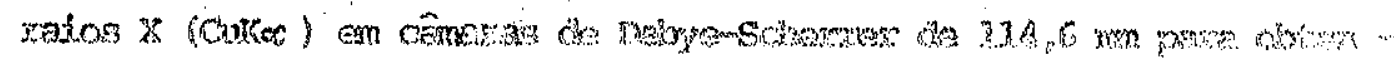
y̆̊

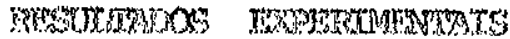

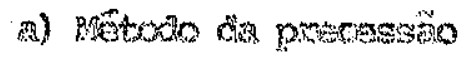

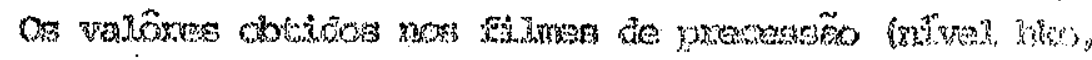

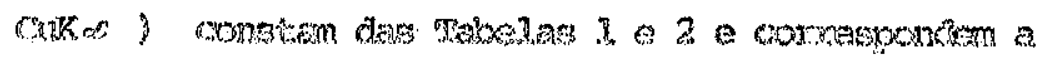
Retrogersises

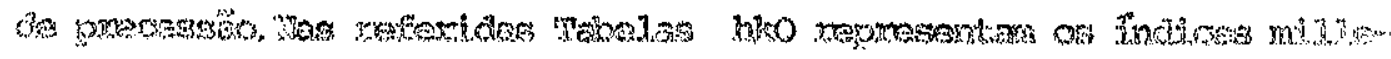

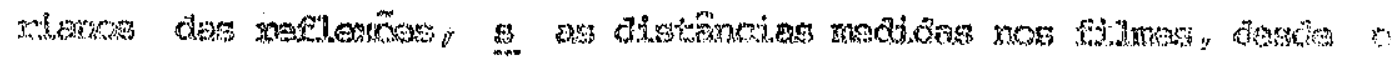

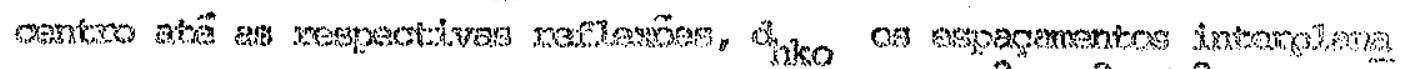

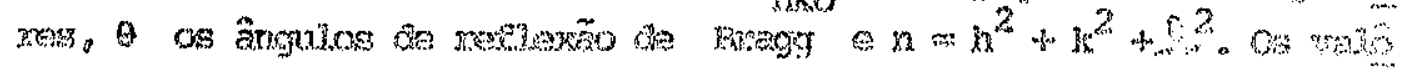
mas ind

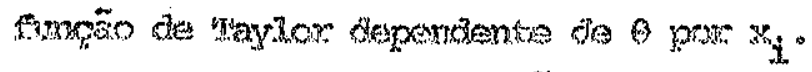

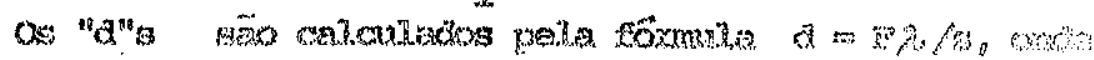

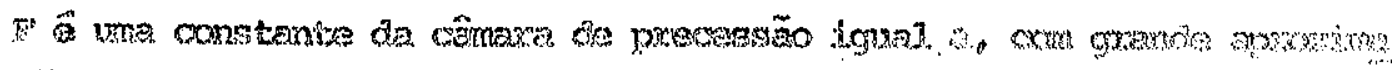

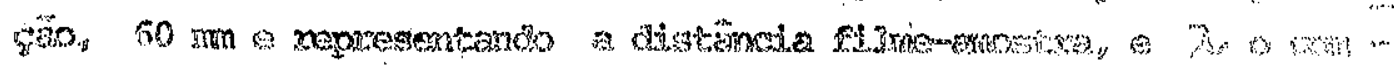

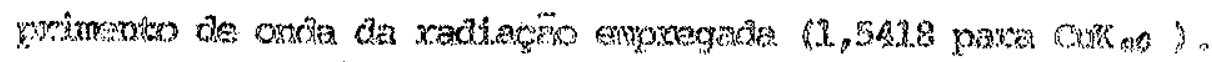

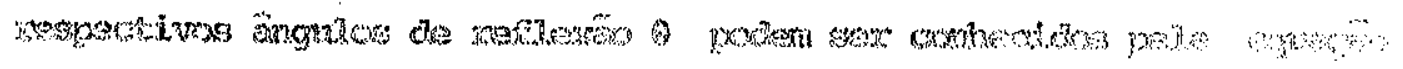




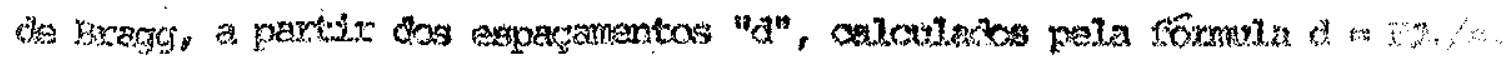

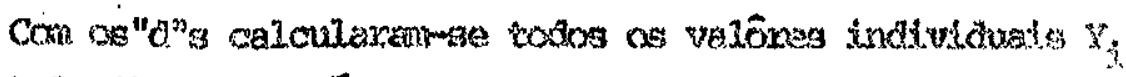

parmotrox (Mabelo 1 ), pelas fromala:

$$
a=a_{0} / \sqrt{h^{2}+k^{2}+12}=a_{0} / \sqrt{n}=y_{3} / \sqrt{n}
$$

de cands

$$
y_{4}=a \sqrt{n}
$$

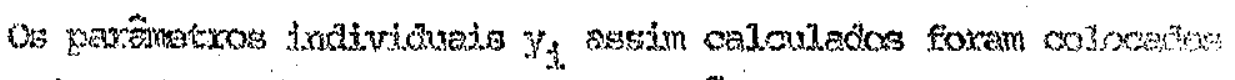

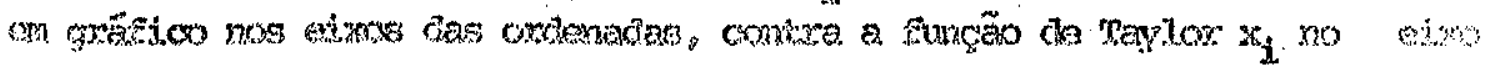

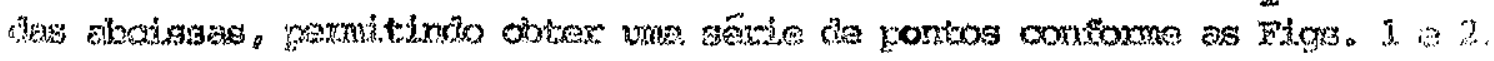

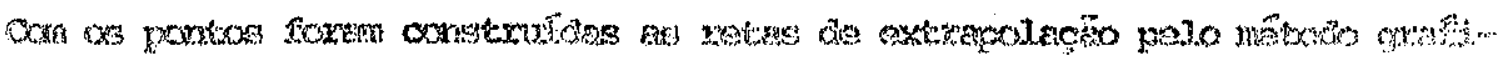

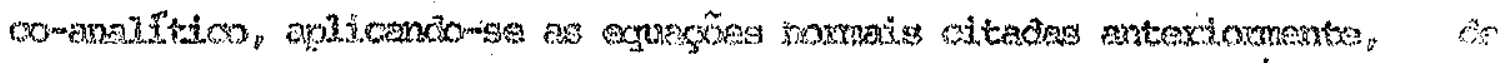

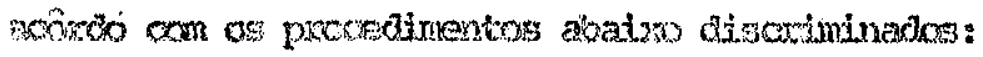

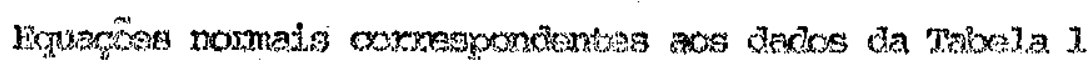

$$
\begin{aligned}
& 180,892 t+50,005 \mathrm{~g} \\
& 50,005 t+\quad 27 \mathrm{p}=200,893
\end{aligned}
$$

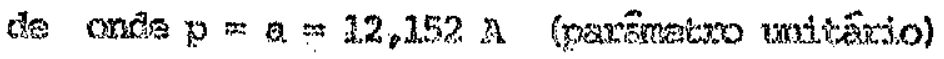

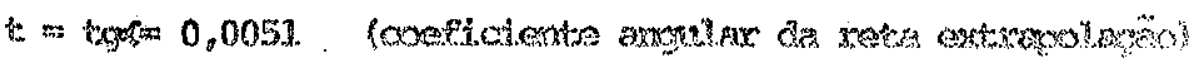

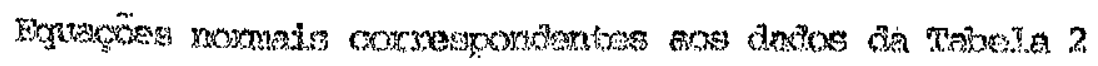

$$
\begin{aligned}
& 380,669+499,974 \mathrm{p}=600,047 \\
& 490,978 \text { to } 4 \quad 27 \mathrm{p}=206,709
\end{aligned}
$$

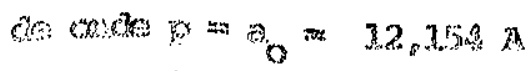

$$
\therefore=0,00035
$$

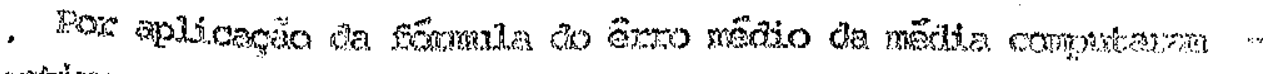

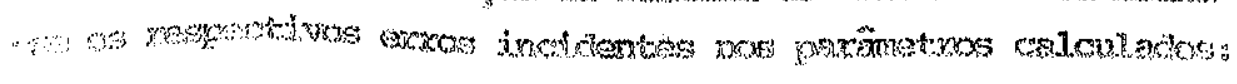




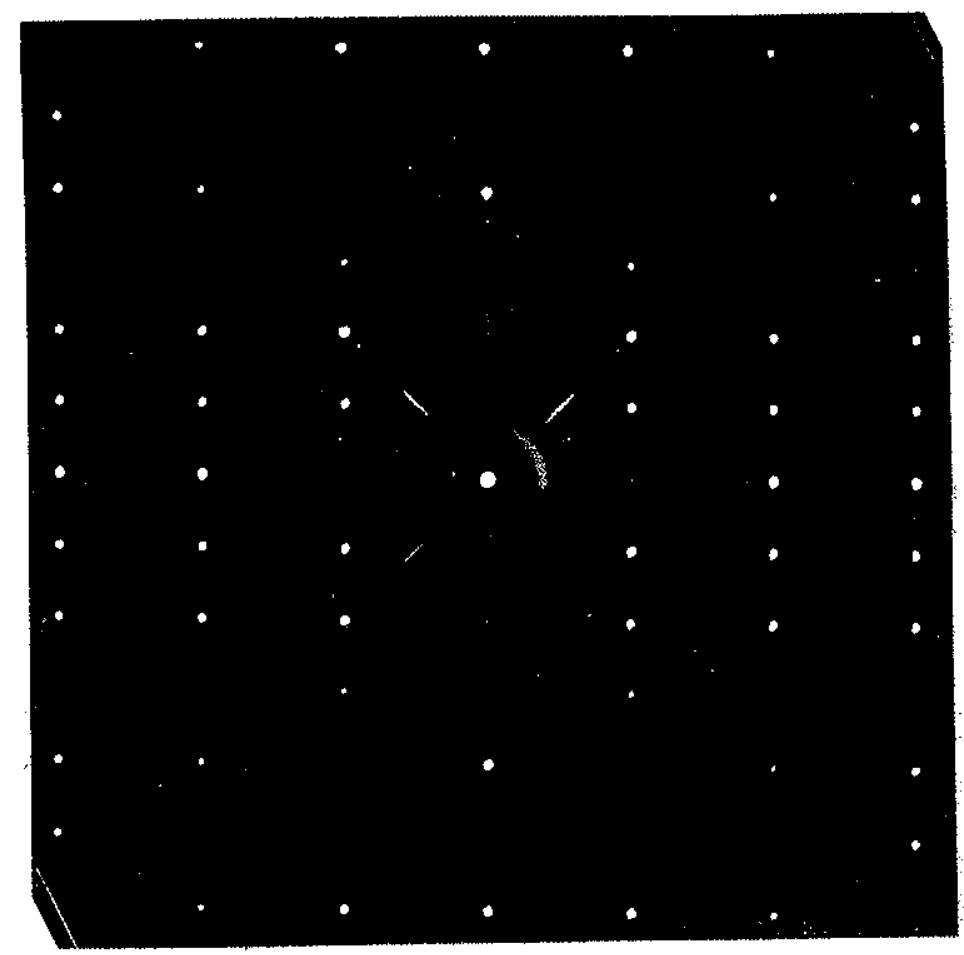

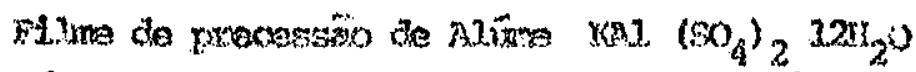

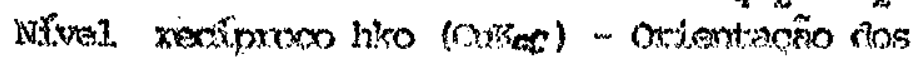

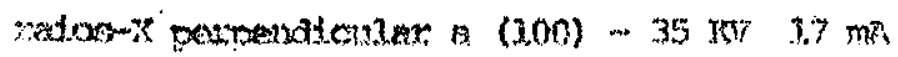

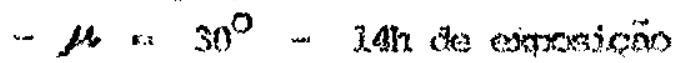




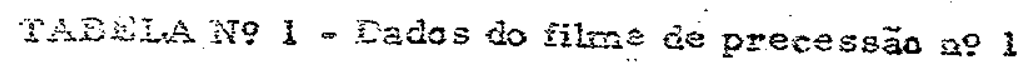

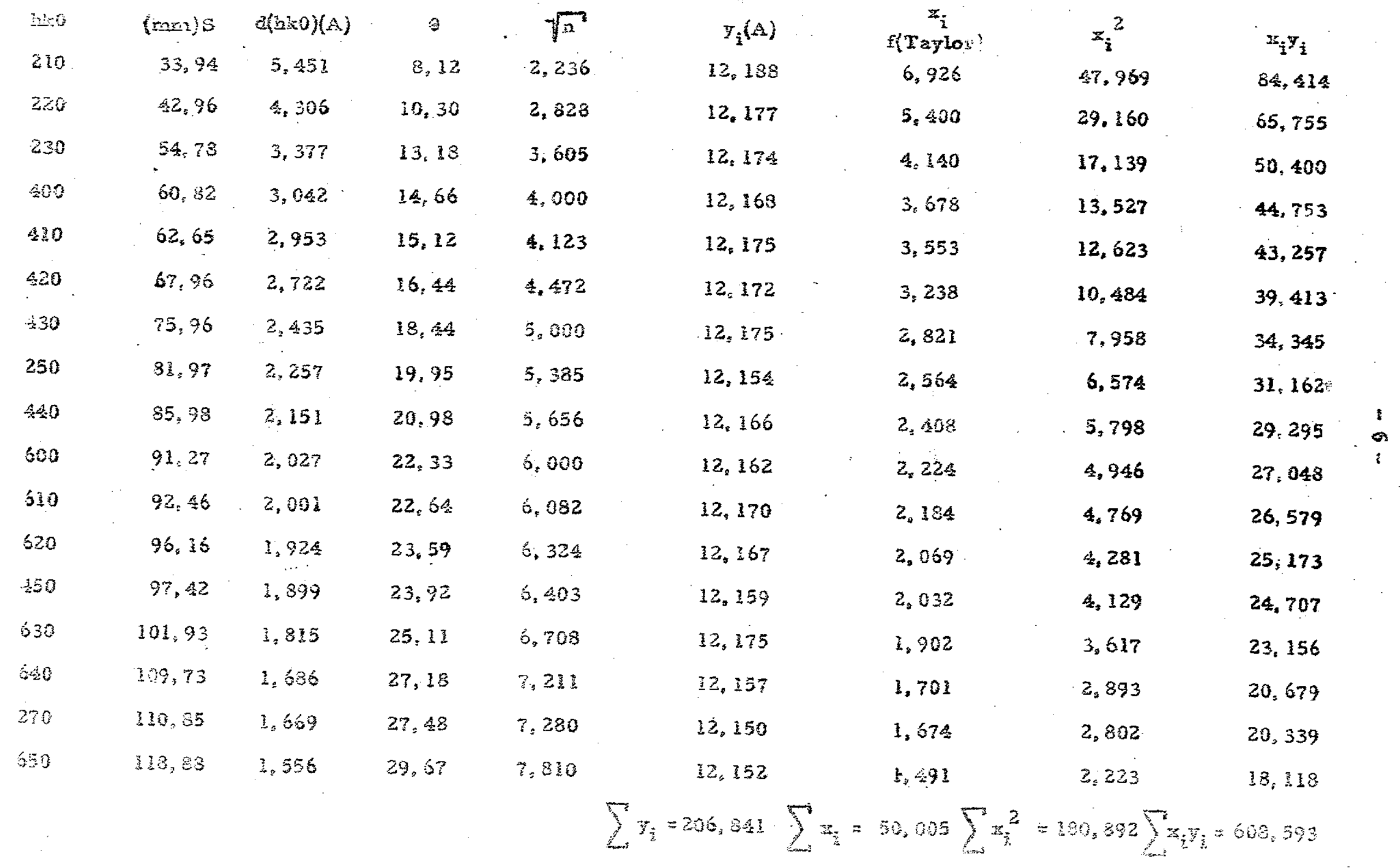




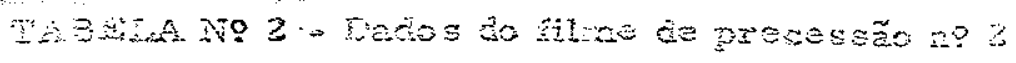

\begin{tabular}{|c|c|c|c|c|c|c|c|c|}
\hline $\mathrm{not}$ & $(m+1)$ & $3(250)(A)$ & 3 & $\sqrt{n}$ & $\bar{y}_{3}(A)$ & $\begin{array}{c}z_{i} \\
\text { (Taylox) }\end{array}$ & $x_{i}^{2}$ & $x_{i} y_{i}$ \\
\hline 230 & 33.95 & 5.650 & 3.12 & 2.236 & 12,136 & 6,926 & 47.969 & 84,800 \\
\hline 220 & 43,00 & $a, 303$ & 10,31 & 2,828 & 32,369 & 5,396 & 29.317 & 65,66 \\
\hline 320 & 5 s. 35 & 3,373 & 13,20 & 3,605 & 12,160 & 4,133 & 17.082 & 50,257 \\
\hline 1800 & 60,80 & 3,083 & 14.66 & $\$, 000$ & 12,172 & 3.678 & 13.528 & 44,769 \\
\hline $4 \geq 0$ & 62.70 & 2.951 & 15,13 & 4,23 & 12.167 & 3.550 & 12.603 & 43,193 \\
\hline 420 & 68,50 & $2,7 \geq ?$ & 16,47 & $A=472$ & 12,250 & 3.222 & 10,381 & 39,147 \\
\hline 239 & 75,75 & 2,435 & $18: A \hat{3}$ & 5.000 & 12,180 & 2.223 & 7,969 & 34.384 \\
\hline 320 & 82,00 & 3,256 & 19,96 & 5,385 & 22,149 & 2,562 & 5,564 & 31.126 \\
\hline 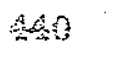 & 36.05 & 2,150 & 20.99 & 5.656 & 12,360 & 2,307 & 5,794 & 29,269 \\
\hline 600 & 91,20 & 2,029 & 22.31 & 6,000 & 12,374 & 2.220 & 4.955 & 27,099 \\
\hline 6 & 92.35 & 2,003 & 22.51 & 6,032 & 12,182 & 2,137 & 4,783 & 26,642 \\
\hline 820 & 90,20 & 1,923 & 23,61 & 6.32 A & 12,161 & 2.065 & 4,268 & 25,125 \\
\hline 540 & $97,4 ?$ & 1,898 & 23,94 & 6,503 & 12,153 & 2,028 & $4,1: 7$ & 24,658 \\
\hline 630 & 102,00 & 2,85 & 35,32 & $6: 708$ & 12.368 & 1.901 & 3.634 & 23,131 \\
\hline 600 & 109.75 & 1,686 & 27,18 & 7.213 & 32,158 & 1,701 & 2.893 & 20,683 \\
\hline 230 & 30,82 & 1.570 & 27.56 & 7,280 & 12.353 & 1.676 & 2,809 & 20,372 \\
\hline 650 & 19888 & 3.556 & 29,67 & 5,830 & $22_{s} 35$ & 1,49 & 2.223 & 38.139 \\
\hline
\end{tabular}




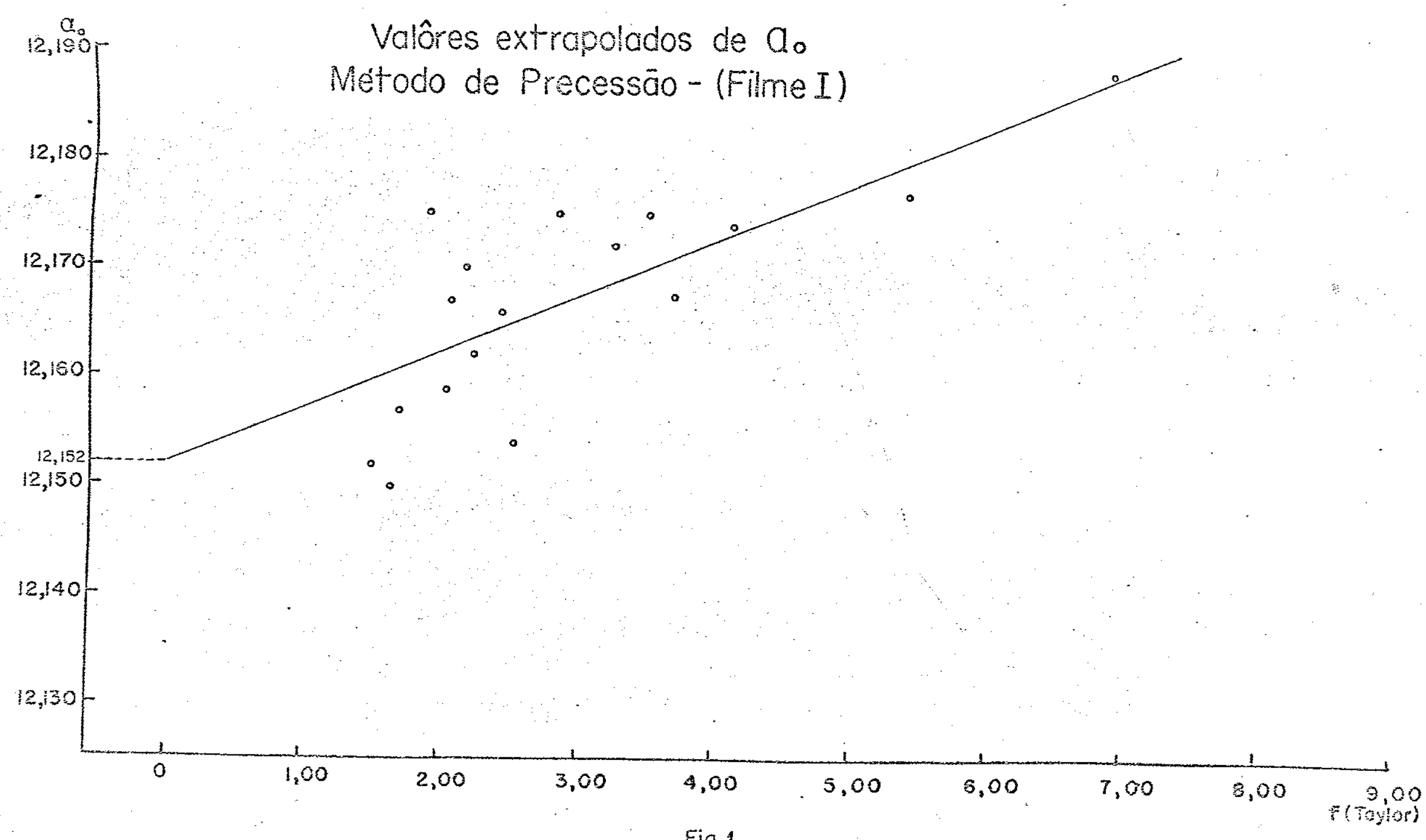

Fig. 1 


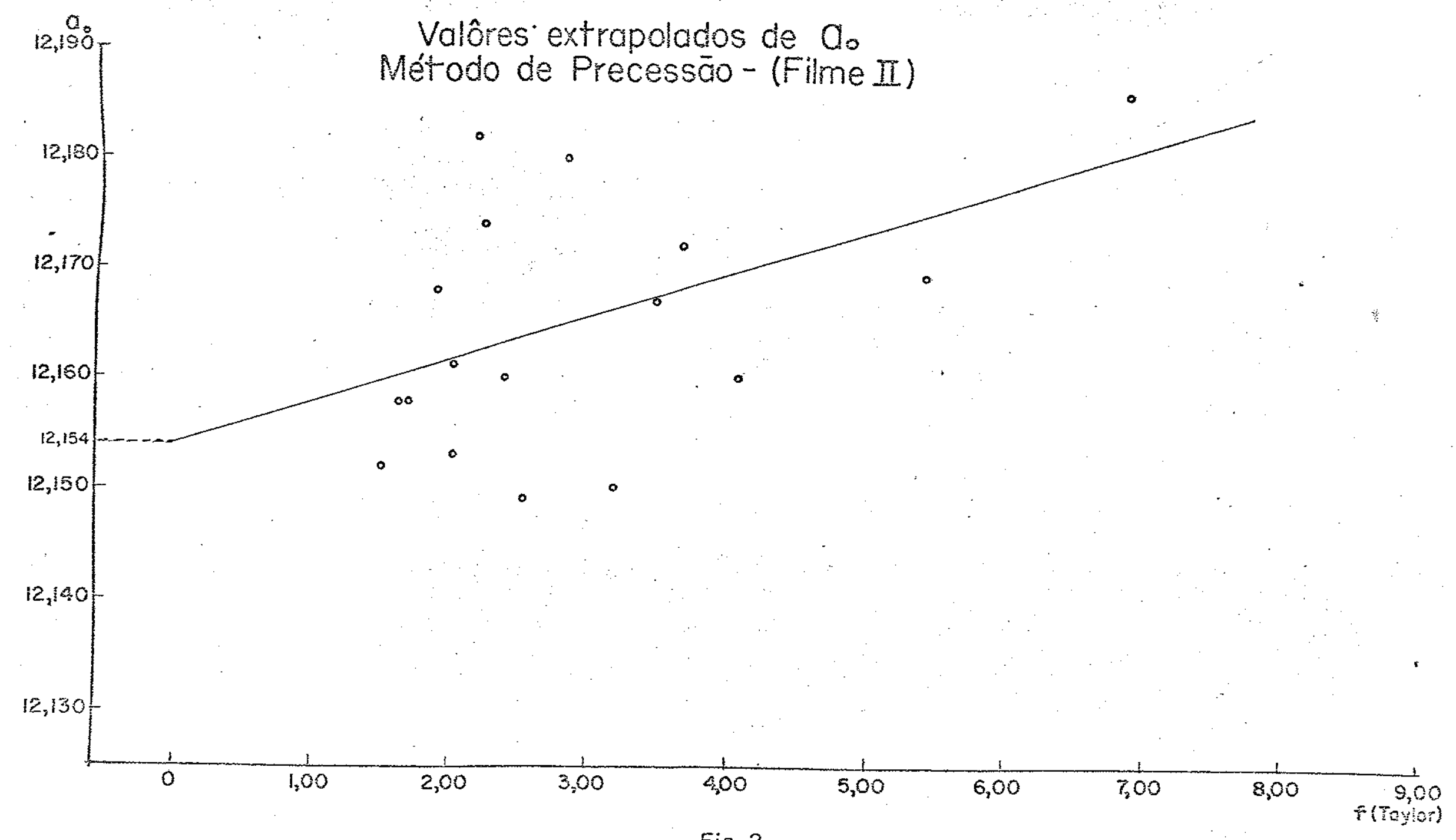

Fig. 2 


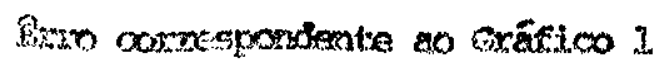

$$
\begin{aligned}
& = \pm \sqrt{\frac{\sum_{1}^{2}}{n(n-1)}} \sqrt{\frac{2527}{37(16)}}=3,05 \mathrm{~m} \\
& 0= \pm 0,0025 \mathrm{~A}=0,002 \mathrm{~A}
\end{aligned}
$$

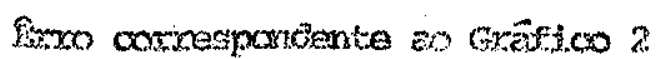

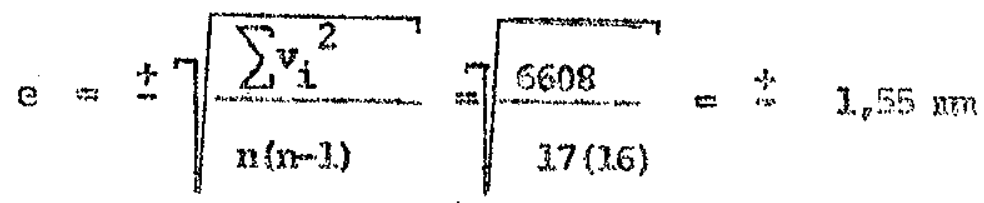

$$
\begin{aligned}
& \mathrm{a}=0,0007 \mathrm{~A}=0,001 \mathrm{~A}
\end{aligned}
$$

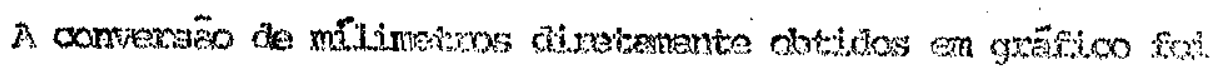

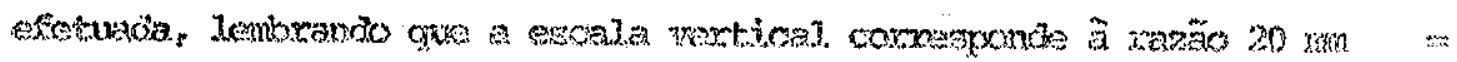
$\because 0,010 \mathrm{~A}$.

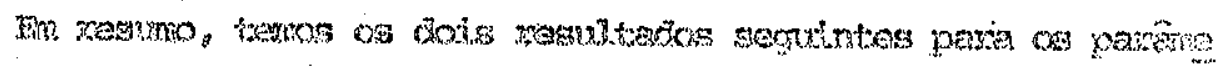

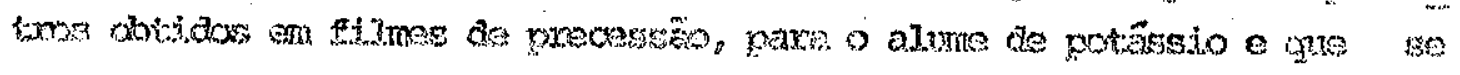

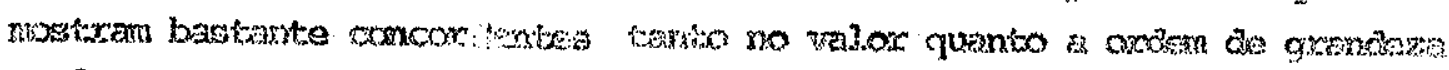
a) فำ:

$$
\text { aris. }
$$

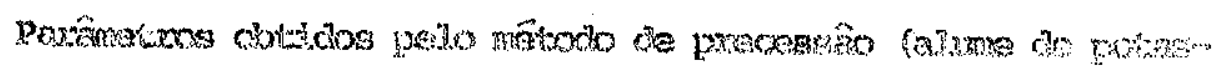

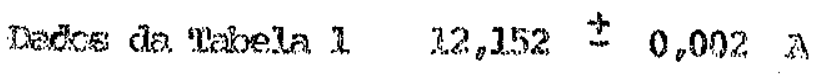

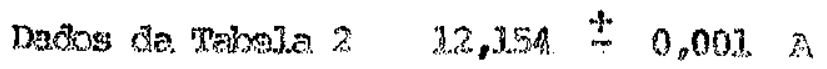

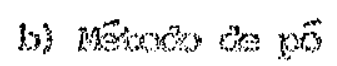

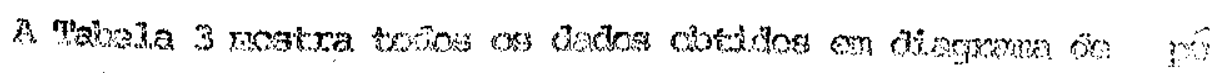

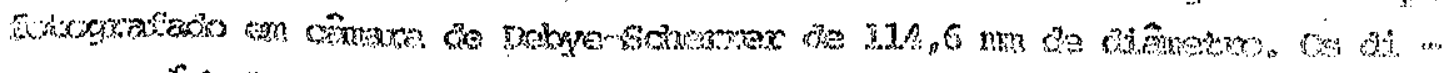

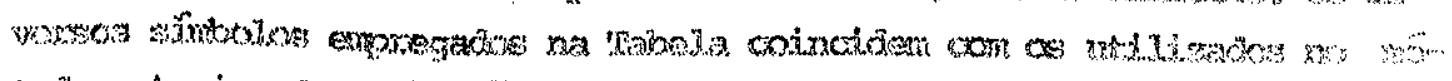

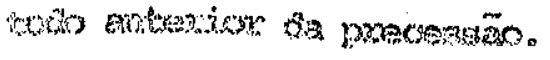

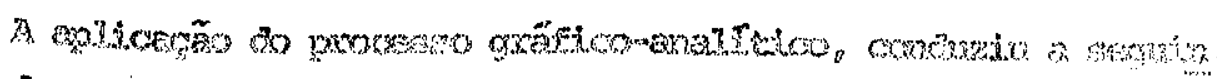

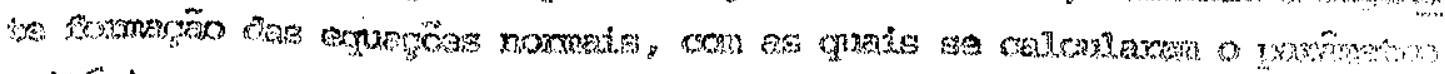

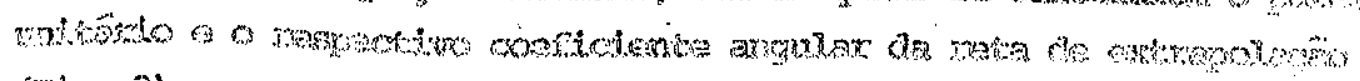
03,39 


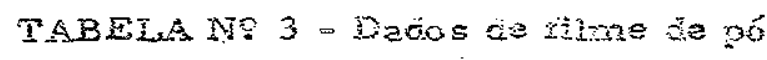

\begin{tabular}{|c|c|c|c|c|c|c|c|c|c|c|}
\hline$I / T_{0}$ & 29 & $t_{\text {lizl }}$ & $3=1$ & $\sqrt{22}$ & $\underline{y}_{i}$ & 3ิ & 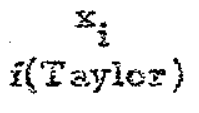 & $\underline{x}_{i}^{\ddot{z}}$ & $z_{i} Y_{i}$ & \\
\hline$i$ & 12,62 & 7,003 & 111 & 1.732 & 12,138 & 6,35 & 8.979 & 30,622 & 108,939 & \\
\hline$\tilde{3}$ & 16,20 & 5,836 & 230 & 2.235 & 12,34 & 8,15 & 6.900 & 97,610 & 83,773 & \\
\hline 2 & $17: 33$ & 4.970 & 211 & 2.449 & 12,172 & 8,92 & 6.281 & 39,450 & 76.152 & \\
\hline 30 & 20,65 & 4298 & 220 & 2,328 & 12,155 & 10,33 & 5,383 & 28,977 & 65,430 & \\
\hline$?$ & 21,90 & $A, 055$ & 221 & 3,000 & 12,165 & 10,95 & 5,059 & 25,593 & 61,543 & \\
\hline$i$ & 24,24 & 3.669 & 313 & 3.317 & 12,170 & 12,12 & 4,530 & 20,593 & $55,22 ?$ & \\
\hline 9 & 27.43 & 3,253 & 321 & 3,732 & 12,265 & $33,7 \underline{3}$ & 3,956 & 15,713 & 48,223 & \\
\hline 3 & 29,37 & 3,038 & $\$ 00$ & 4,000 & 12,352 & 14,69 & 3.670 & 13.469 & 44,598 & \\
\hline 3 & 30,27 & 3.950 & $\Delta 10$ & 4.23 & 12,163 & 15,14 & 3,558 & 12,588 & A3, 154 & \\
\hline 2 & $3 i, 20$ & 2,864 & 411 & $s_{i} 2 \leq 3$ & 12,152 & 15,60 & 3,429 & 11,758 & 41,670 & \\
\hline 6 & 32,05 & 2,790 & 331 & $4_{s} 359$ & 12,162 & 16,03 & 3.324 & 11.049 & 40.426 & \\
\hline 3 & 32,90 & 2.720 & 420 & $4,4+2$ & 12,164 & 15,45 & 3.226 & 10,407 & 39,241 & \\
\hline 2 & 33,72 & 2,656 & 423 & 4583 & 12,172 & 16.86 & 3,135 & 9.828 & 38,159 & \\
\hline$\vdots$ & 34,63 & 2,588 & 332 & 然 690 & 12.138 & 37,32 & 3,038 & 9.229 & 36.875 & \\
\hline 1 & 30,38 & 2。余8 & 422 & 6.390 & 128754 & 18.09 & 2.885 & 8,323 & 5,064 & \\
\hline 0,5 & 37,72 & 2.383 & 431 & 3.099 & 12,151 & 18,82 & 2,752 & 7.573 & 33.439 & \\
\hline 3 & 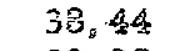 & $2,3 \leq 0$ & 513 & 5,196 & 32,359 & 59,22 & 2,634 & 7.204 & 32,635 & t \\
\hline 0.5 & 39,72 & 2,256 & 432 & 5,395 & 12,149 & 19.96 & 2,562 & 6,285 & 30,457 & 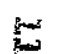 \\
\hline 1 & 40,62 & 2,257 & 528 & 5,877 & 12,153 & 20,31 & 2.307 & 6.370 & $30,67 \%$ & 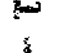 \\
\hline 0.5 & 82,76 & 2,133 & 522 & 5,745 & 12,139 & 21,33 & 2,351 & 5,527 & 28,539 & \\
\hline 0.5 & $43,\{4$ & 2,083 & 433 & 5.831 & 12,134 & 21,72 & 2,302 & 5,299 & 27,932 & \\
\hline 2 & 44,76 & 2,023 & 800 & 5, 000 & 12,138 & 22,38 & 2,238 & 4,919 & 26.922 & \\
\hline$\xi$ & 45,39 & 1,996 & 610 & 6,083 & 12,142 & 22,70 & $2.17 ?$ & 4,739 & 26,433 & \\
\hline 2 & 46,01 & 1,771 & 631 & 6,164 & 12,349 & 23,01 & 2,139 & 4,575 & 25,987 & \\
\hline 4 & $\$ 7,23$ & 1.923 & 620 & 6,325 & 12,163 & $23,6 i$ & 2,067 & 4,272 & 25,141 & \\
\hline 2 & 49,12 & 1.853 & 533 & 6.557 & 32,150 & 24,56 & 1.960 & $3,3 \leqslant 2$ & 23,814 & \\
\hline 9,5 & $49,6 ?$ & 4,934 & 622 & 6,633 & 32,165 & 24,84 & 1.930 & $3, ? 25$ & 23,478 & \\
\hline 2 & 34,43 & 3,635 & $6 A 0$ & 3,211 & 12,153 & $27,2 \overline{3}$ & 1.698 & 2.883 & 20,632 & \\
\hline
\end{tabular}




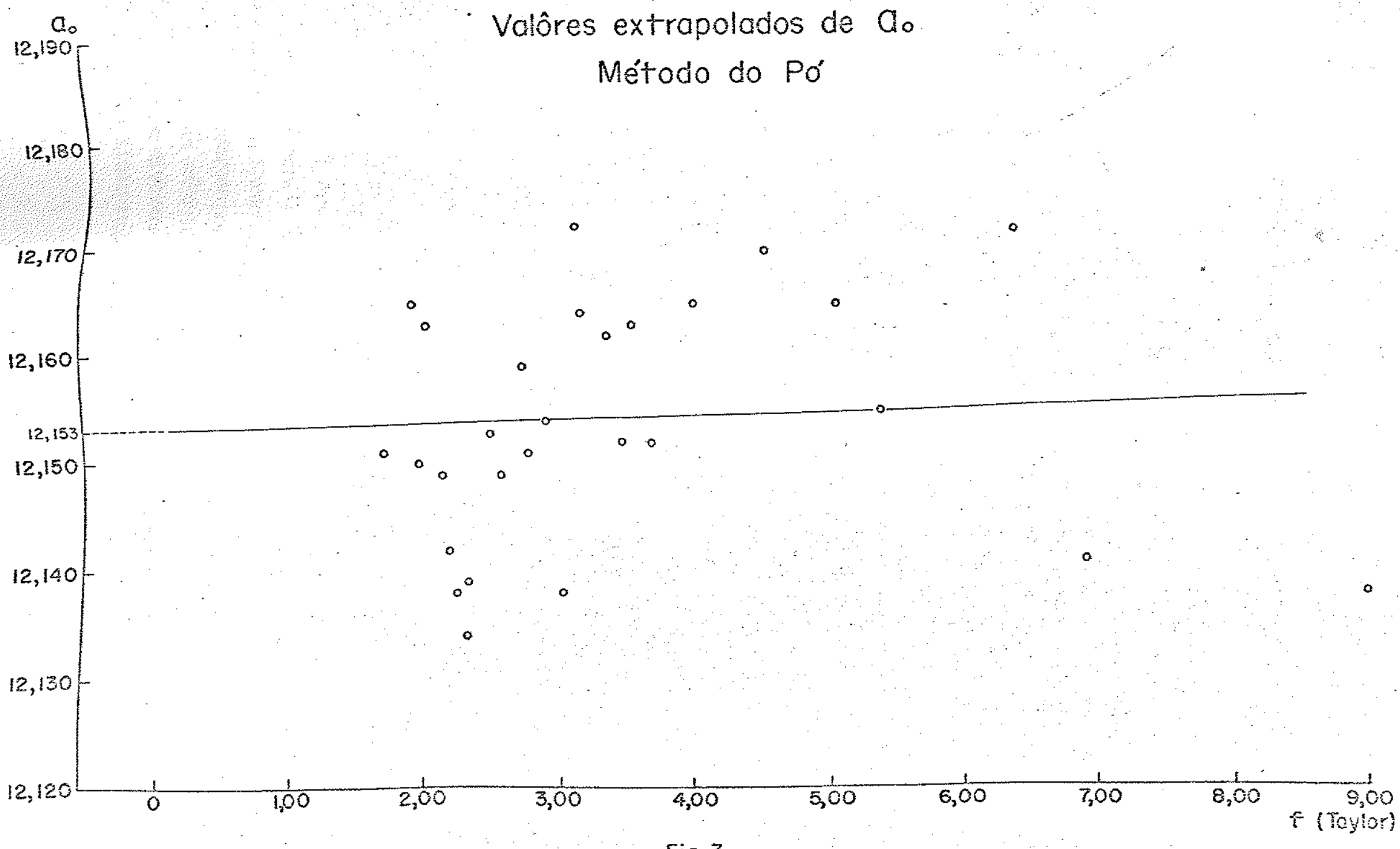

Fig. 3 


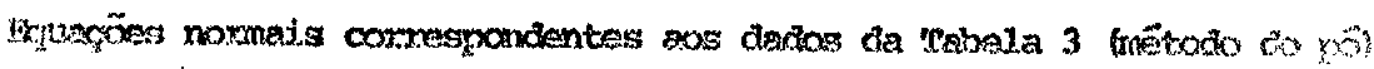

$$
\begin{array}{r}
412,422 t+96,668 p=1174,904 \\
96,668 t+\quad 28 p=340,306
\end{array}
$$

de onde $p=a_{0}=32,153 \mathrm{~A}$ (partênetro unitisio)

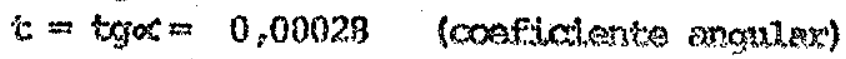

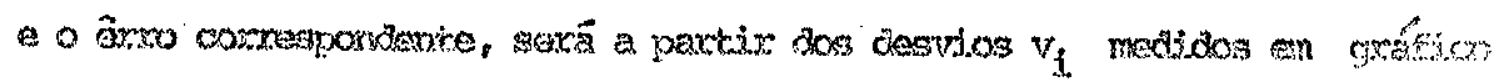

$$
\begin{aligned}
& e= \pm \sqrt{\frac{v_{0}^{2}}{n(x-2)}}=\sqrt{\frac{14061}{26272}}=i 0_{3} 3 \mathrm{~mm} \\
& a=0,002 A
\end{aligned}
$$

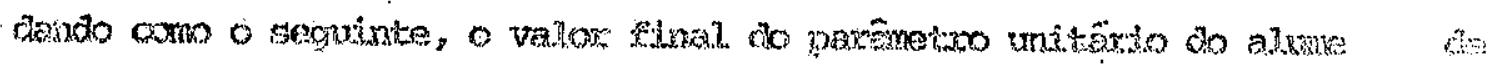
protêgto, calrulado polo mécodo do p:

$$
a_{0}=12,253+0,002:
$$

ondrstus

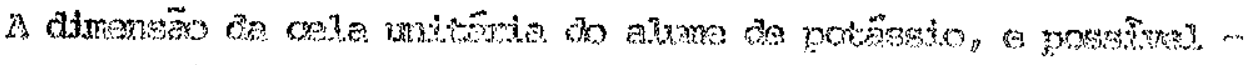

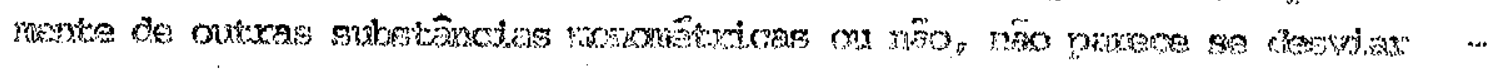

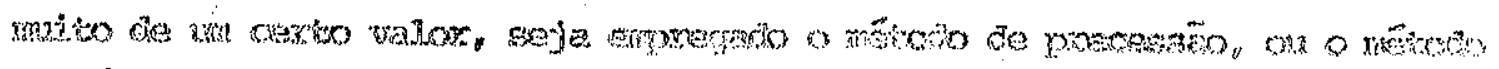

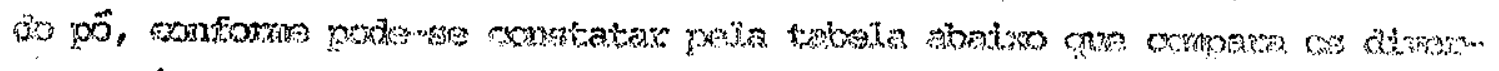

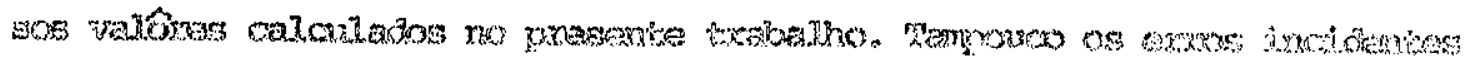

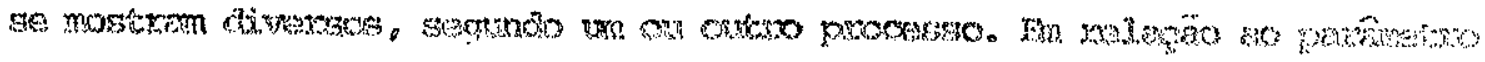

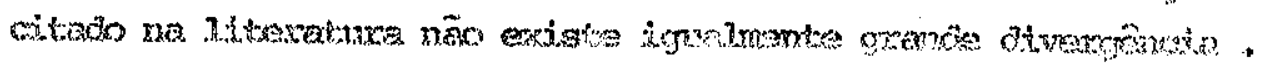




\section{Patînatros mitärios do alume potäsgio:}

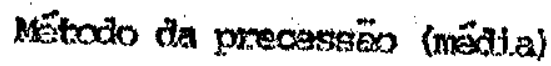 \\ Metodo do pó \\ Kling e Azexandar (1990)
}

$$
\begin{aligned}
& 12,153 \pm 0,002 \mathrm{~A} \\
& 12,353 \pm 0,002 \mathrm{~A} \\
& 12,358 \pm 0,003 \mathrm{~A}
\end{aligned}
$$

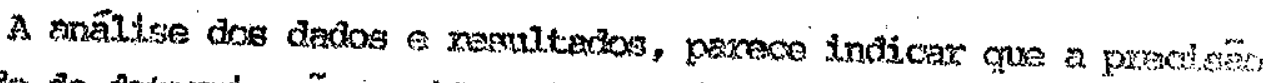

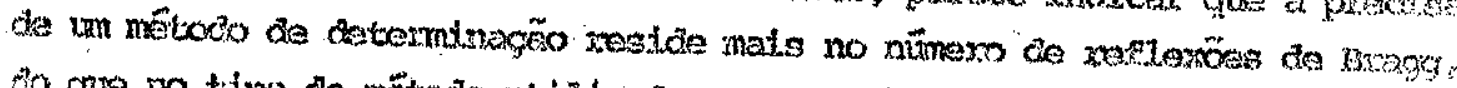

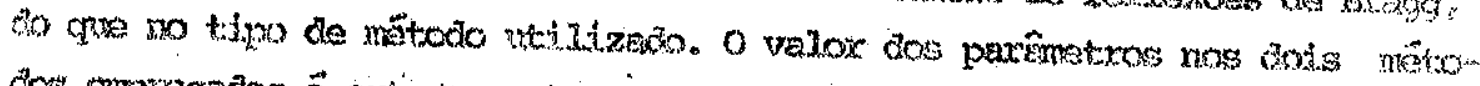

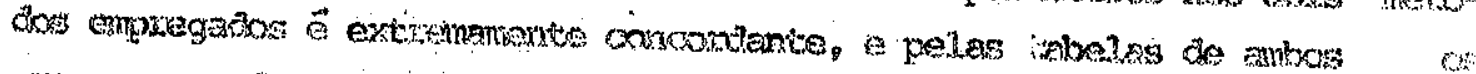

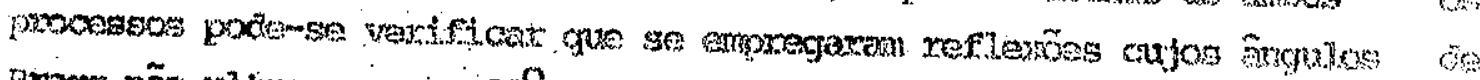

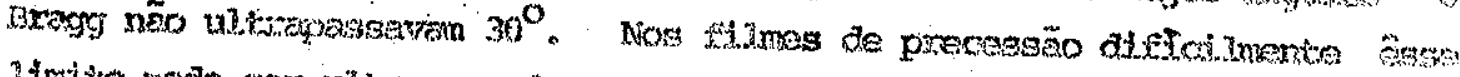

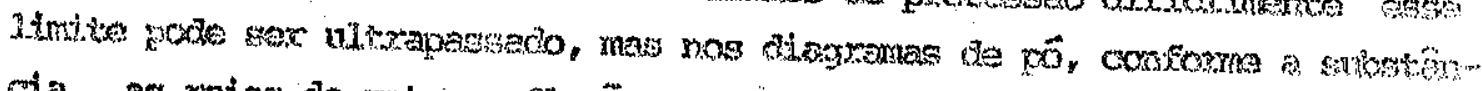

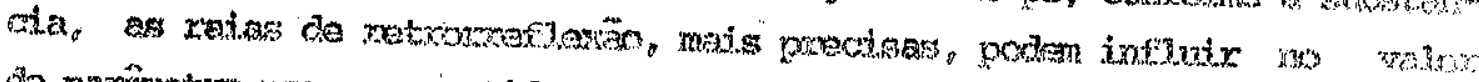

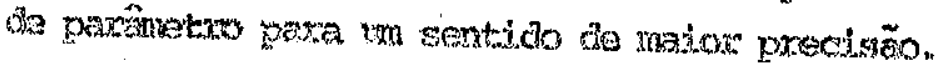

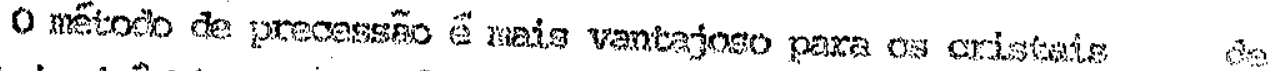

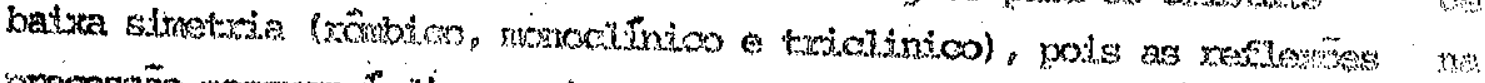

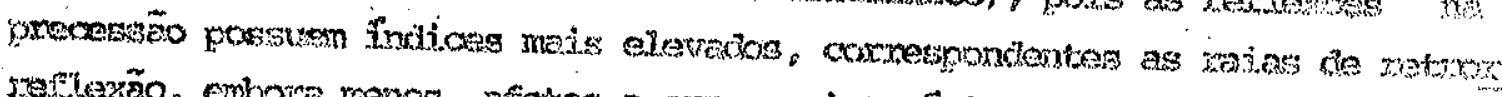

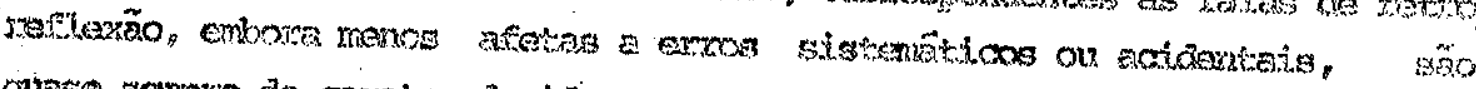

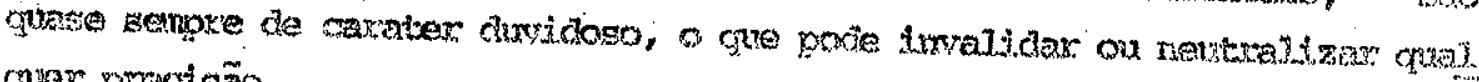
crax proxisão.

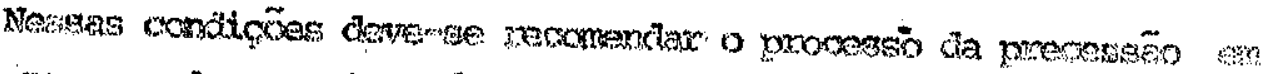

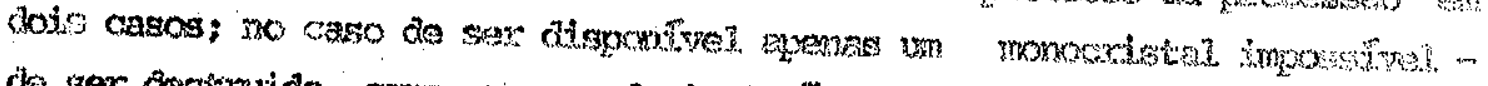

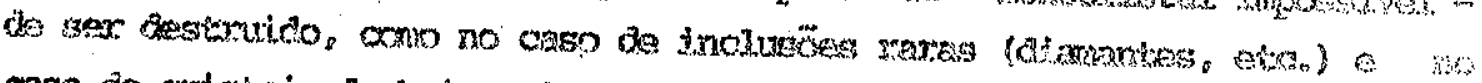

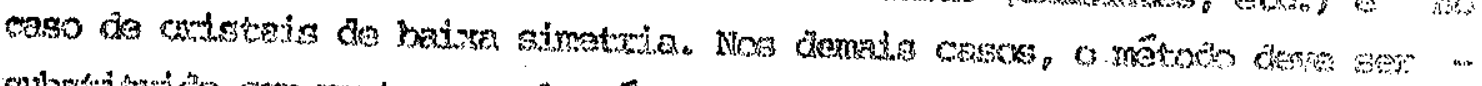

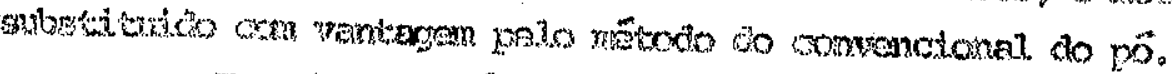

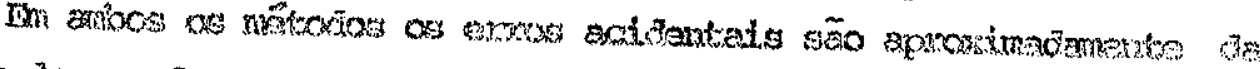

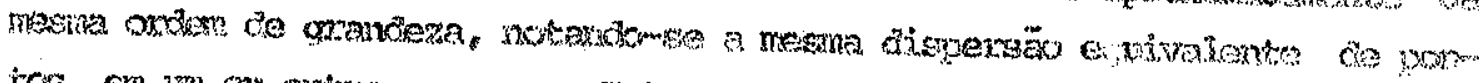

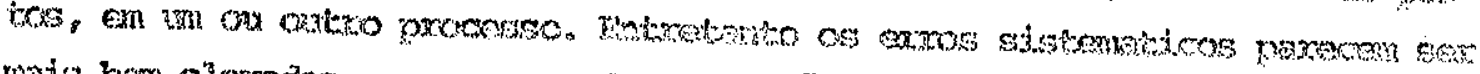

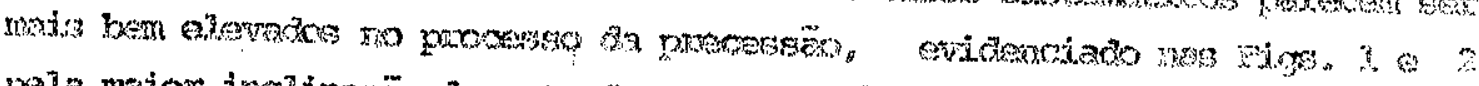

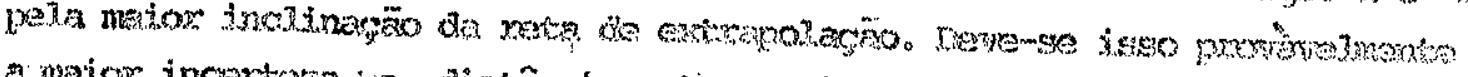

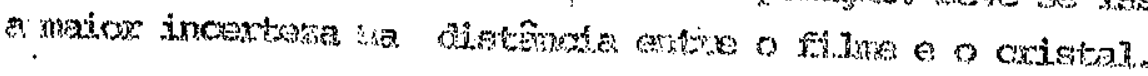




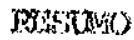

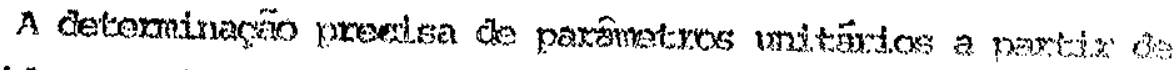

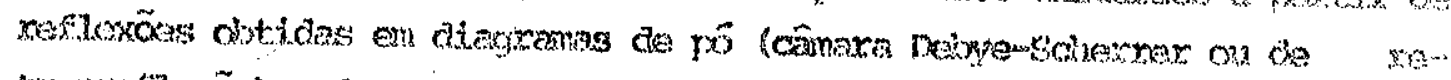

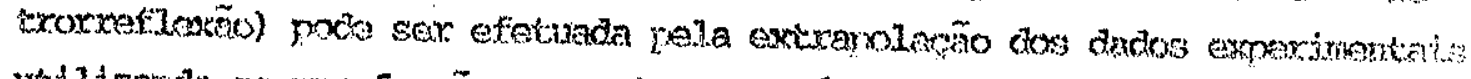

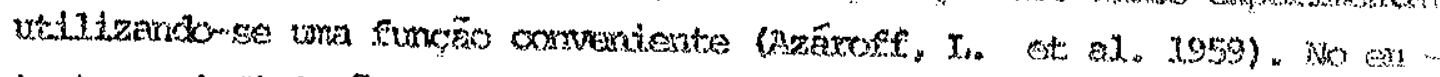

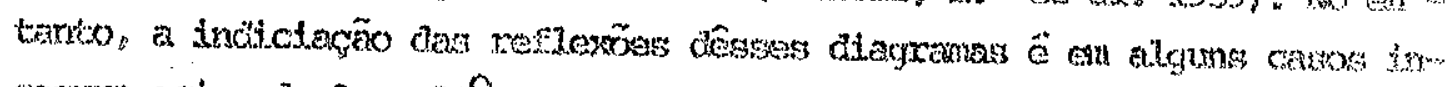

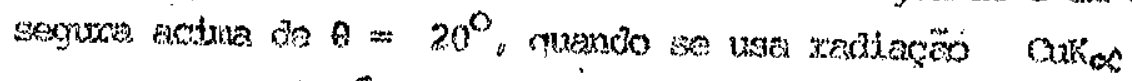

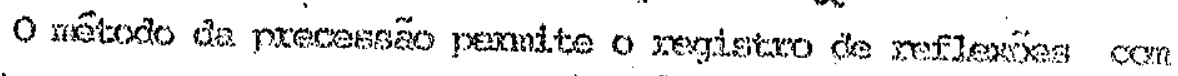

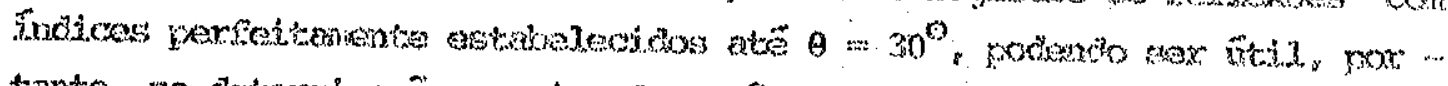

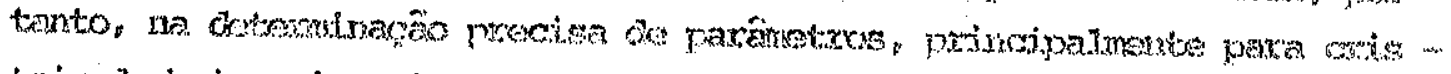
lata de beisea sirkoturia.

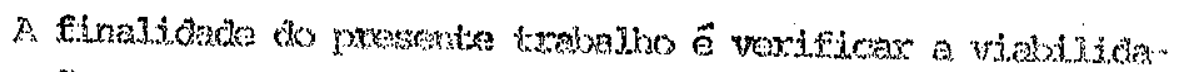

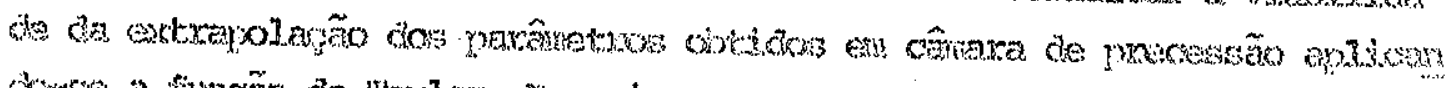

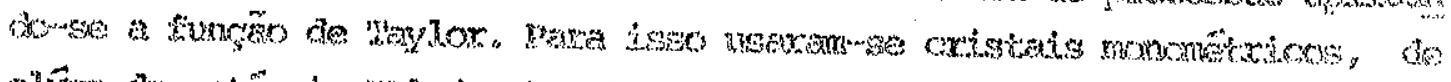

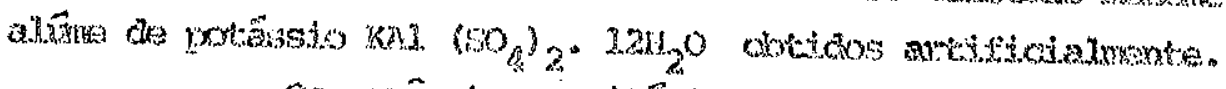

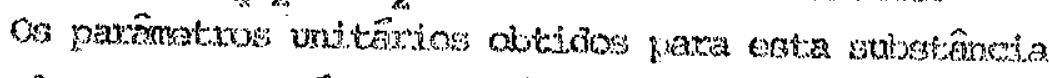

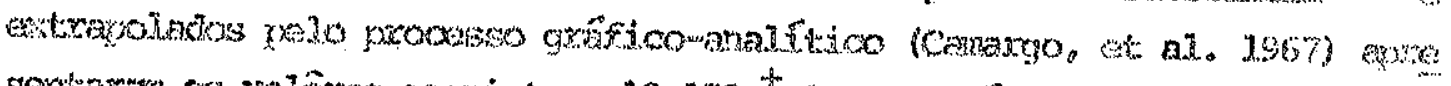

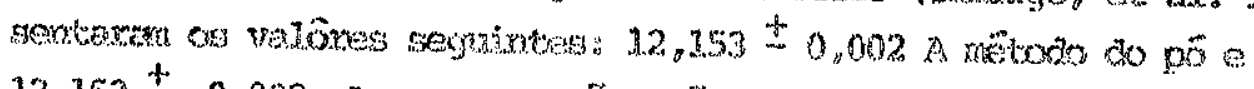

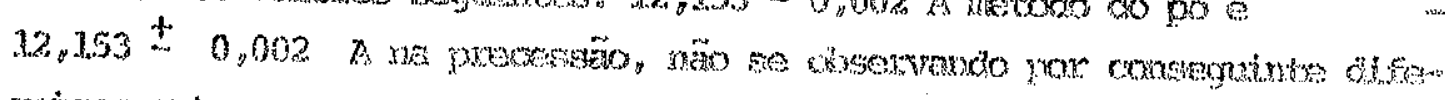

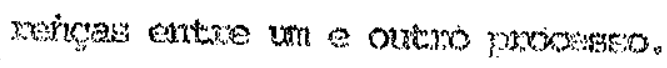

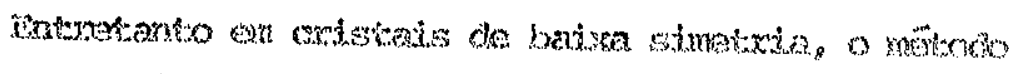

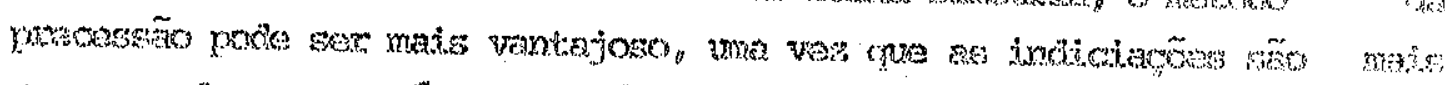

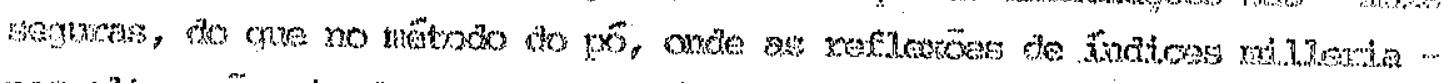

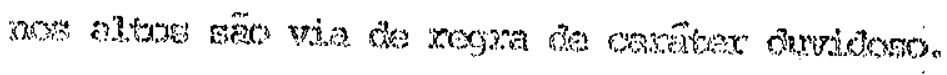


2GRACHCTMARTos

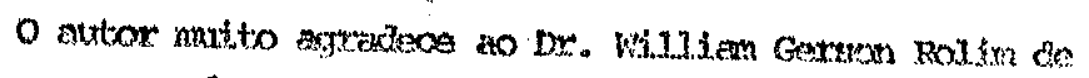

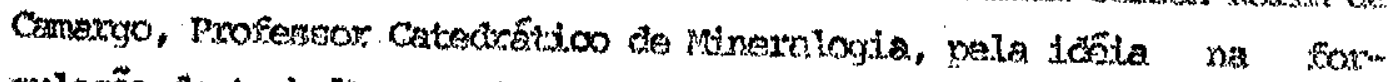

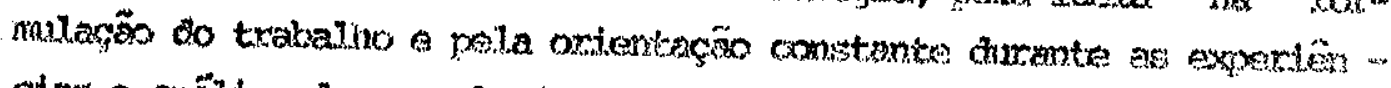

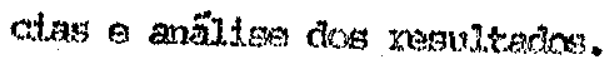

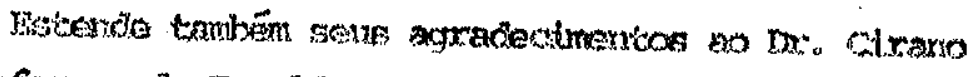

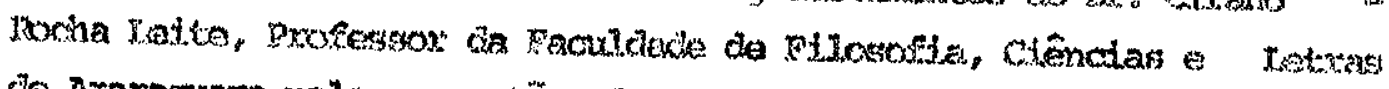

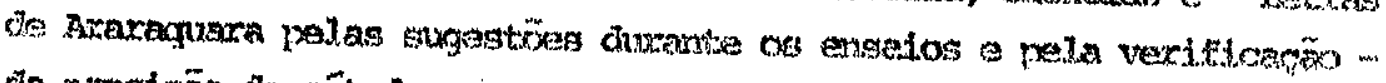
co prextsão do metoxio. 


\section{B.IIIOSRAFXA}

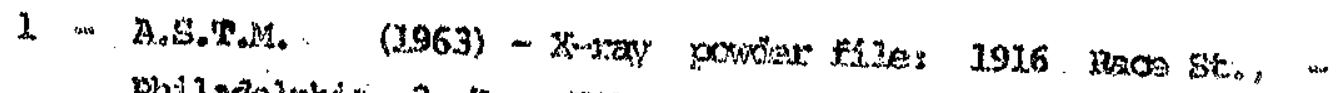

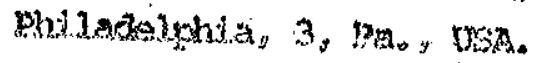

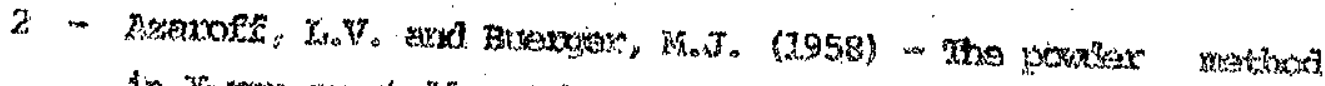

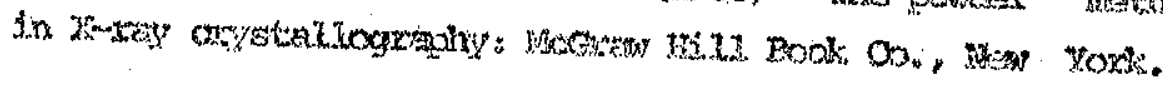

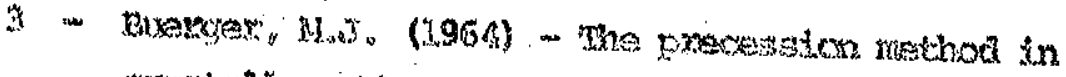

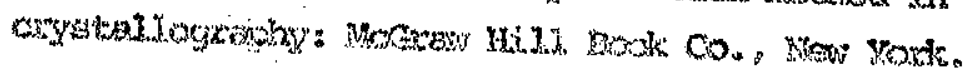

xw.r.

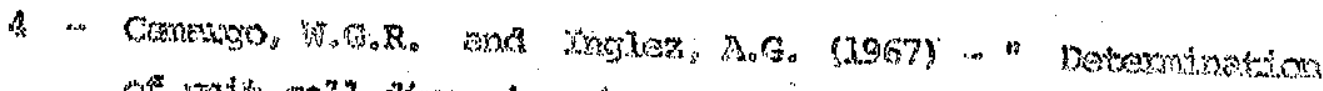

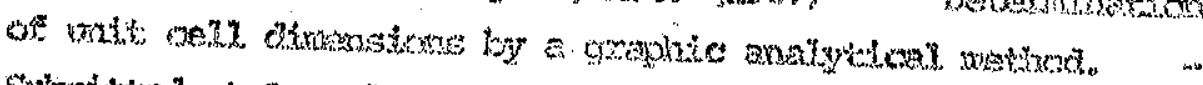

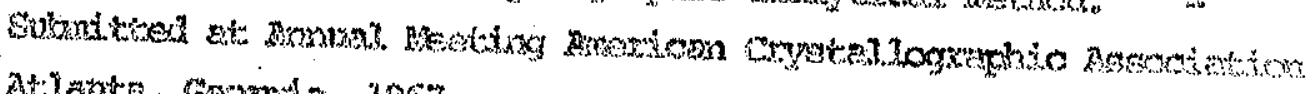
Atombs.

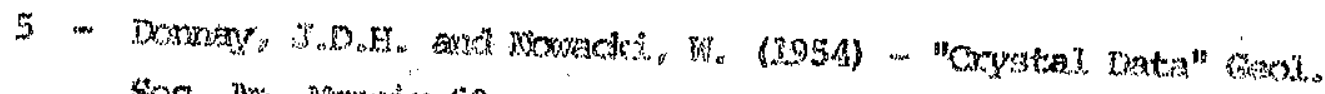

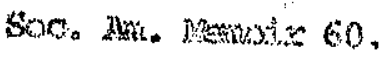

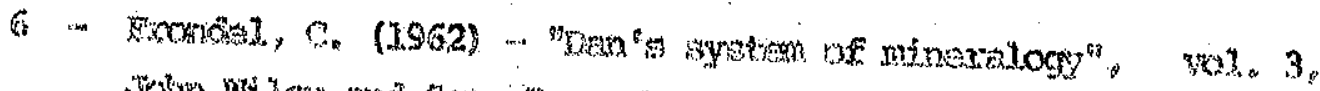

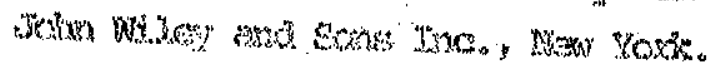

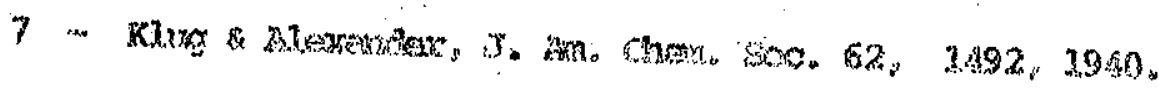

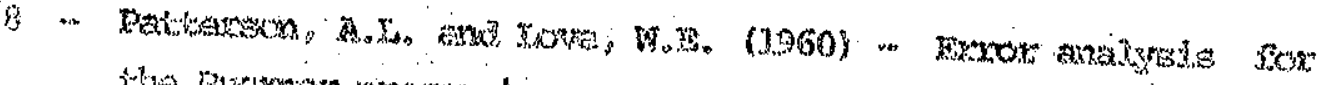

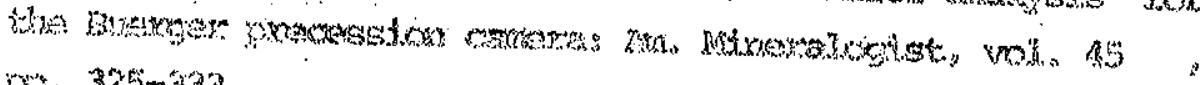
$3 \% 325-323$

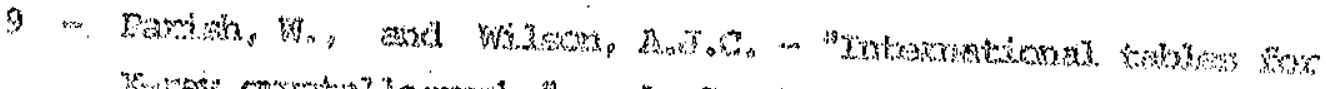

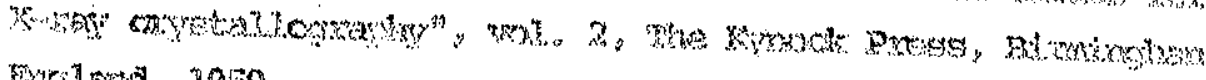

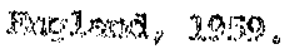

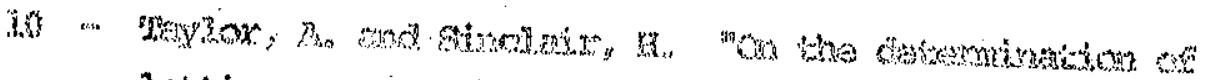

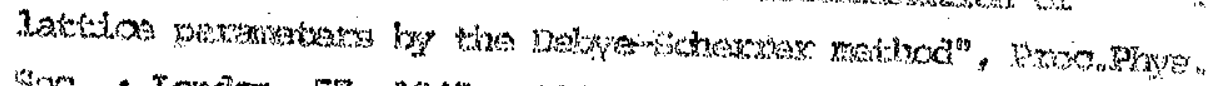

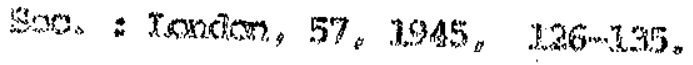

